\title{
Improve the Efficiency and Open Circuit Voltage of Triple Junction Gaas Solar Cell with Anti Reflector Layer
}

\author{
Bita Farhadi ${ }^{1}$, Tahereh Abasi ${ }^{1}$, Rozita Farhadi ${ }^{1 *}$, Niloofar Sadeghi ${ }^{2}$, Behnam Tahmasebi \\ Esmati $^{1}$, Saba Ebrahimpanah ${ }^{3}$ \\ ${ }^{1}$ Young Researchers and Elite Club, Kermanshah Branch, Islamic Azad University, Kermanshah, Iran \\ ${ }^{2}$ Zagros Institute of Higher Education, Kermanshah, Iran \\ ${ }^{3}$ Electrical Engineering Department, Faculty of Engineering, Razi University, Tagh-E-Bostan, Kermanshah, \\ Iran
}

*Corresponding Author: Rozita Farhadi, Young Researchers and Elite Club, Kermanshah Branch, Islamic Azad University, Kermanshah, Iran

\begin{abstract}
In this paper, we first study the structure and operation of solar cells with three junctions based on GaAs, we then consider some important parameters like efficiency, Fill factor, short circuit current and open circuit voltage. Indeed, Solar cell or photovoltaic cell is a device which directly converts the photovoltaic effect to the electricity. Solar modules and photovoltaic arrays are used for constructing solar panels among all cells. Moreover, photovoltaic is a technology and research area that is related to the solar cells application in a electricity generation for practical using.In addition, the energy generation by using this method is an example of solar power.
\end{abstract}

Keywords: Photovoltaic, solar cells, Fill factor, GaAs, Anti reflector.

\section{INTRODUCTION}

Since solar cells are more applicable in electricity preparation (AC) using photovoltaic powerhouse and providing necessity energy for devices that need lower voltage, so operational improvement of them are more important. At first multi-junction solar cells with high efficiency are designed for specific applications like satellites and spatial discovering, but currently, they are the lowest cost selection for using in Terrestrial concentrator.These multi-junction solar cells consist of multi thin layers which are generated by Epitaxy method. Till now, GaAs multi-junction devices are more efficient solar cells.

\section{OPTICAL LIGHT SOURCES IN ELECTRONICS AND TELECOMMUNICATIONS}

Sets are both originally from the middle of the composition of aluminum, gallium, arsenic, germanium, phosphorus, antimony, $\mathrm{Si}$ with different proportions and the degree of concentration is obtained. understand the basic principles of light sources telecommunications, optical phenomena in absorbing the radiation we describe the spontaneous and stimulated emission. Atom or the semiconductor crystal, the absorption of certain wavelengths of light in the form of electromagnetic waves or will be free. Know that a semiconductor has three valence band and the conduction band energy of prohibited conduct are that if you call E1 and E2 and the valence band the electron energy band E2 is the energy of the conduction band energy band E2 to E1, light with a frequency proportional to the energy difference E2-E1 is absorbed or released by Ibn frequency from the following equation derived, Figure 1 illustrated the proposed structure.

$\mathrm{F}=\mathrm{e} 2-\mathrm{e} 1 / \mathrm{h}$.

International Journal of Research Studies in Electrical and Electronics Engineering (IJRSEEE) Page | 1 


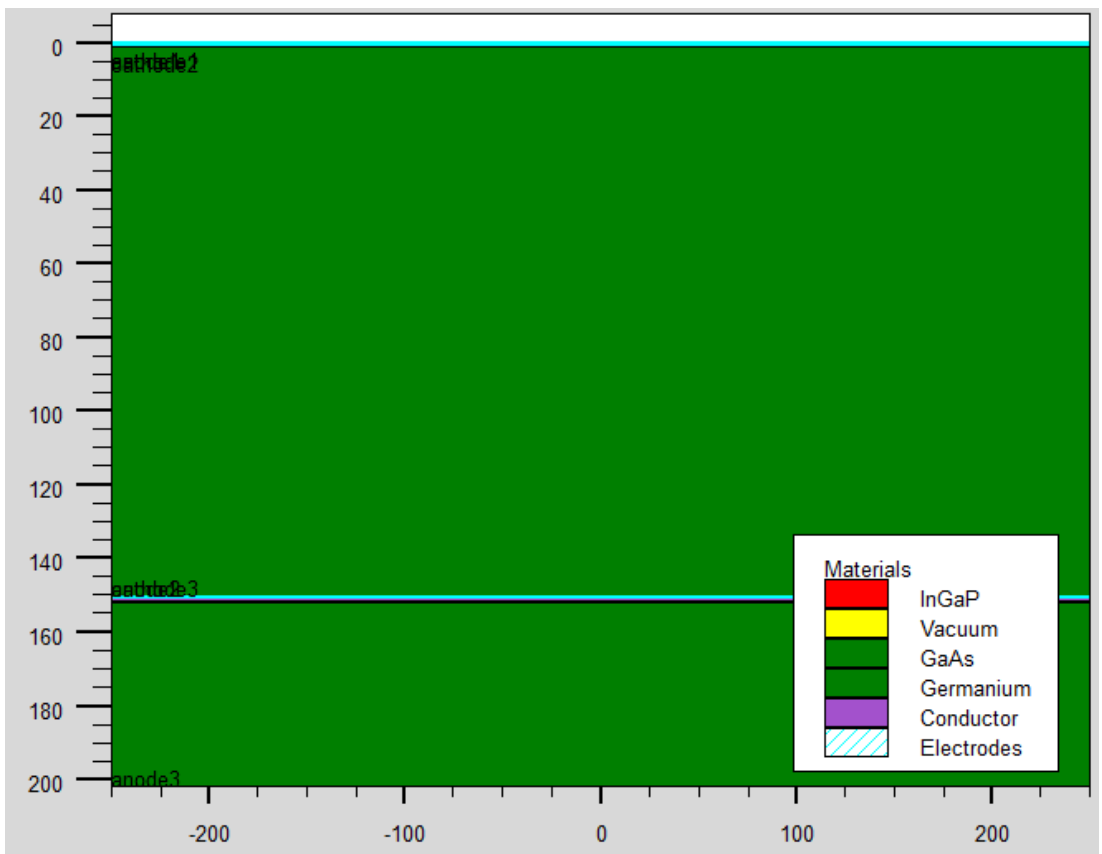

Figure1. Proposed structure

\section{Proposed SOlarCELl STRUCTURE}

Solar cell that LED can also say, like typical diode, connecting two semiconductor p-type and $\mathrm{n}$ are constructed with different junction semiconductor materials wearing black is, but because it light junction semiconductors will usually " it by the glass or transparent plastic cover. Be installed on most photo diode a very small lens to focus light into the area and can link to the site. photo diode a light detector that may be required depending on the light energy is converted into electrical current. photo diodes very similar to the diodes semiconductor usual, with the difference that the diodes in photon could also be exposed to light energy ( $x$-ray or uv) be and can be optical fiber connections shall be mounted to light the areas of critical is entered, it should be noted that the structure of the photon diode diode that is built into the pin connection used to link the pn. $\mathrm{N}$-type silicon is the basic material. A thin layer of $\mathrm{P}$, using thermal diffusion or ion implantation doping with suitable material (typically boron) on the upper surface of the tool is installed. The thickness of this layer must be represented by the wavelength of the radiation is determined. $\mathrm{P}$ and $\mathrm{N}$ silicon boundary layer is known as the PN bond. Small metal fitting on the upper level and all the instruments are mounted on the back is coated with a metallic connection. Back connection, cathode and connectivity front, the anode. Active surface of the silicon nitride or silicon monoxide or silicon dioxide is coated for protection and to prevent reflections. The thickness of the cladding layer is specific for a particular emission wavelength. PN link capacity depends on the thickness of the depletion region. Reverse bias voltage increases, the thickness of this region increases, the capacity is reduced (as long as it does not create conditions for full discharge). Link capacity, as well as the specific resistance of the silicon active area. Photo diodes basis is actually a link PN or PIN structure the area is called sweeping .Thus holes move toward the anode, and electrons toward the cathode, and a stream of light (photo current) is created. Photovoltaic mode, the diode at zero bias or photovoltaic mode, go to work, the luminous flux (photo current ) is restricted and a voltage builds . In this case, the diode is forward biased and" dark current" (currents this is that in the absence of light photons diode) light in the opposite direction of the flow will begin to flow. This mode is induced photovoltaic effect is the basis for solar cells. Indeed Cell a diode with a large area of solar panels. photo conductive mode or optical semiconductor diode is reverse biased in this fashion usually quickly reduces the response time will increase the noise. This, in turn, increase the width of the depletion region, which in turn reduces the link capacity and the response speed is faster. Reverse bias induces only a small amount of current for a while during constant light (figuratively, of course). Linearly with the light intensity is proportional. Although it is faster, more electronic noise shows photo conductive mode. In figure 2 and table 1 show the J-V curve and output parameters of proposed structure, respectively. 
Improve the Efficiency and Open Circuit Voltage of Triple Junction Gaas Solar Cell with Anti Reflector Layer

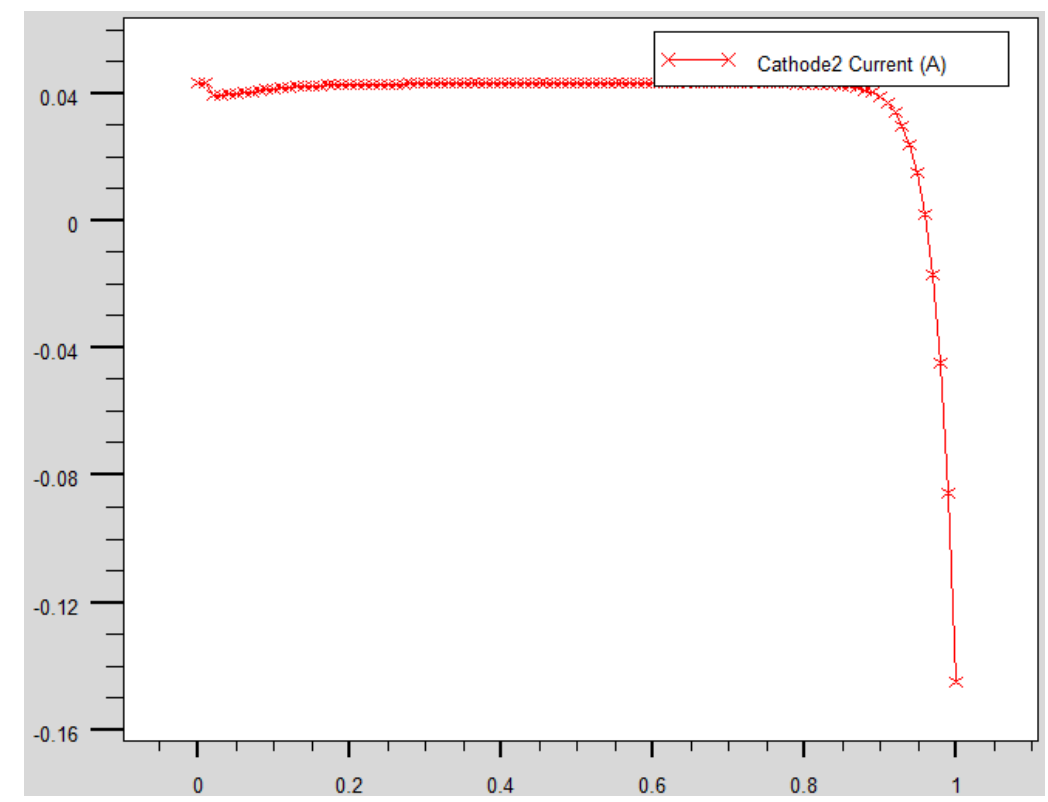

Figure2. The J-V curve of proposed structure

Table1. The output parameters of proposed structure

\begin{tabular}{|c|c|}
\hline $\mathrm{J}_{\mathrm{SC}}\left(\mathrm{mA} / \mathrm{cm}^{2}\right)$ & 41.305 \\
\hline $\mathbf{V}_{\mathbf{O C}}(\mathbf{V})$ & 1.0002 \\
\hline $\mathbf{F F}(\boldsymbol{\%})$ & 88.2489 \\
\hline $\boldsymbol{\eta}(\boldsymbol{\%})$ & 26.670 \\
\hline
\end{tabular}

\section{Photovoltaic mode}

When the diode at zero bias or photovoltaic mode, go to work, the luminous flux (photo current) is restricted and a voltage is created. In this case, the diode is forward biased and "dark current" begins to flow in the opposite direction of the flow of light. These materials, photovoltaic effect.

The effect of impurity thickness and density on various physical and electrical parameters of the solar cell was investigated. We will now examine the results of the simulation with respect to changes in the geometric characteristics of the solar cell. Tables 2 and 3 show the results of numerical analysis.

Table2. Parameters extracted from the simulation due to the change in emitter layer thickness.

\begin{tabular}{|c|c|c|c|c|}
\hline Emitter thickness & 0.1 & 0.2 & 0.4 & 0.8 \\
\hline $\mathbf{J}_{\mathbf{S C}}\left(\mathbf{m A} / \mathbf{c m}^{2}\right)$ & $\mathbf{4 2 . 7 7 0 1}$ & $\mathbf{3 5 . 2 0 0 2}$ & $\mathbf{4 3 . 0 0 8}$ & 27.6004 \\
\hline $\mathbf{V}_{\text {OC }}(\mathbf{V})$ & $\mathbf{1}$ & $\mathbf{1}$ & $\mathbf{1}$ & 1 \\
\hline FF (\%) & $\mathbf{8 6 . 2 7 5 4}$ & $\mathbf{8 3 . 0 9 6 5}$ & $\mathbf{8 7 . 8 9 0 6}$ & 81.5217 \\
\hline $\boldsymbol{\eta}(\%)$ & $\mathbf{2 6 . 9 9 9 3}$ & $\mathbf{2 1 . 4 0 1 9}$ & $\mathbf{2 7 . 6 5 7 8}$ & 16.4630 \\
\hline
\end{tabular}

Table3. Parameters extracted from the simulation due to the change in the thickness of the base layer.

\begin{tabular}{|c|c|c|c|c|}
\hline Base thickness & 100 & 120 & 140 & 150 \\
\hline $\mathbf{J}_{\mathbf{S C}}\left(\mathbf{m A} / \mathbf{c m}^{\mathbf{2}}\right)$ & $\mathbf{2 8 . 8 6 5}$ & $\mathbf{3 . 6 8 7 5}$ & $\mathbf{5 . 9 8 4}$ & 42.77 \\
\hline $\mathbf{V}_{\mathbf{O C}}(\mathbf{V})$ & $\mathbf{1}$ & $\mathbf{1}$ & $\mathbf{1}$ & 1 \\
\hline $\mathbf{F F}(\%)$ & $\mathbf{8 9 . 8 9 0 8}$ & $\mathbf{8 7 . 8 6 4 4}$ & $\mathbf{8 9 . 7 2 9 2}$ & 86.2754 \\
\hline $\boldsymbol{\eta}(\boldsymbol{\%})$ & $\mathbf{1 8 . 9 8 5 1}$ & $\mathbf{2 . 3 7 0 6}$ & $\mathbf{3 . 9 2 8 7}$ & 26.9993 \\
\hline
\end{tabular}

According to the table 4, The best dopingconcentration is $1 \mathrm{e} 17$ for Emitter and 1e18for Base.

Table4. Parameters extracted from the simulation due to the change in impurity density of the base layer

\begin{tabular}{|c|c|c|c|c|}
\hline Base doping concentration & $1 \mathrm{e} 15$ & $1 \mathrm{e} 16$ & $1 \mathrm{e} 17$ & $1 \mathrm{e} 18$ \\
\hline $\mathbf{J}_{\mathbf{S C}}\left(\mathbf{m A} / \mathbf{c m}^{2}\right)$ & $\mathbf{4 0 / 9 1 7 5}$ & $\mathbf{4 2 / 3 5 1}$ & $\mathbf{4 3 / 0 2 5}$ & $43 / 1$ \\
\hline $\mathbf{V}_{\mathbf{O C}}(\mathbf{v})$ & $\mathbf{1}$ & $\mathbf{1}$ & $\mathbf{1}$ & 1 \\
\hline $\mathbf{F F}(\boldsymbol{\%})$ & $\mathbf{8 8 / 8 6 1 7}$ & $\mathbf{8 7 / 9 7 9 0}$ & $\mathbf{8 9 / 4 2 4 8}$ & $89 / 6868$ \\
\hline $\boldsymbol{\eta}(\boldsymbol{\%})$ & $\mathbf{2 6 . 6 0 4 2}$ & $\mathbf{2 7 . 2 6 2 7}$ & $\mathbf{2 8 . 1 5 1 7}$ & 28.2834 \\
\hline
\end{tabular}

International Journal of Research Studies in Electrical and Electronics Engineering (IJRSEEE) Page | 3 
Improve the Efficiency and Open Circuit Voltage of Triple Junction Gaas Solar Cell with Anti Reflector Layer

Then we investigation the effect of adding different anti-reflective coatings on InGaP / GaAs / Ge three-junction solar cells. The results of this simulation are shown in the table 5.

Table5. Parameters derived from simulation due to the addition of various anti-reflective coatings.

\begin{tabular}{|c|c|c|c|c|}
\hline Anti-reflector materials & $\mathrm{SiO}_{2}$ & $\mathrm{SiN}$ & $\mathrm{ZnO}$ & $\mathrm{Si}_{3} \mathrm{~N}_{4}$ \\
\hline $\mathbf{J}_{\mathbf{S C}}\left(\mathbf{m A} / \mathbf{c m}^{\mathbf{2}}\right)$ & $\mathbf{4 0 . 7 4 6}$ & $\mathbf{4 1 . 0 8 1}$ & $\mathbf{4 1 . 6 4 4}$ & 43.095 \\
\hline $\mathbf{V}_{\mathbf{O C}}(\mathbf{V})$ & $\mathbf{1}$ & $\mathbf{1}$ & $\mathbf{1}$ & 1.006 \\
\hline $\mathbf{F F}(\boldsymbol{\%})$ & $\mathbf{9 0 . 4 1 3 7}$ & $\mathbf{9 0 . 7 9 7 4}$ & $\mathbf{9 1 . 2 4 9}$ & 89.3699 \\
\hline $\boldsymbol{\eta}(\boldsymbol{\%})$ & $\mathbf{2 6 . 9 5 5 4}$ & $\mathbf{2 7 . 2 9 2 3}$ & $\mathbf{2 7 . 8 0 4}$ & 28.3493 \\
\hline
\end{tabular}

Figure 3 and Table 5 compares the IV diagram of the cell with different reflective coatings, By adding Si3N4 anti-reflective coating, we were able to return the efficiency to $28.3493 \%$ That has increased compared to single-link mode and other covers.

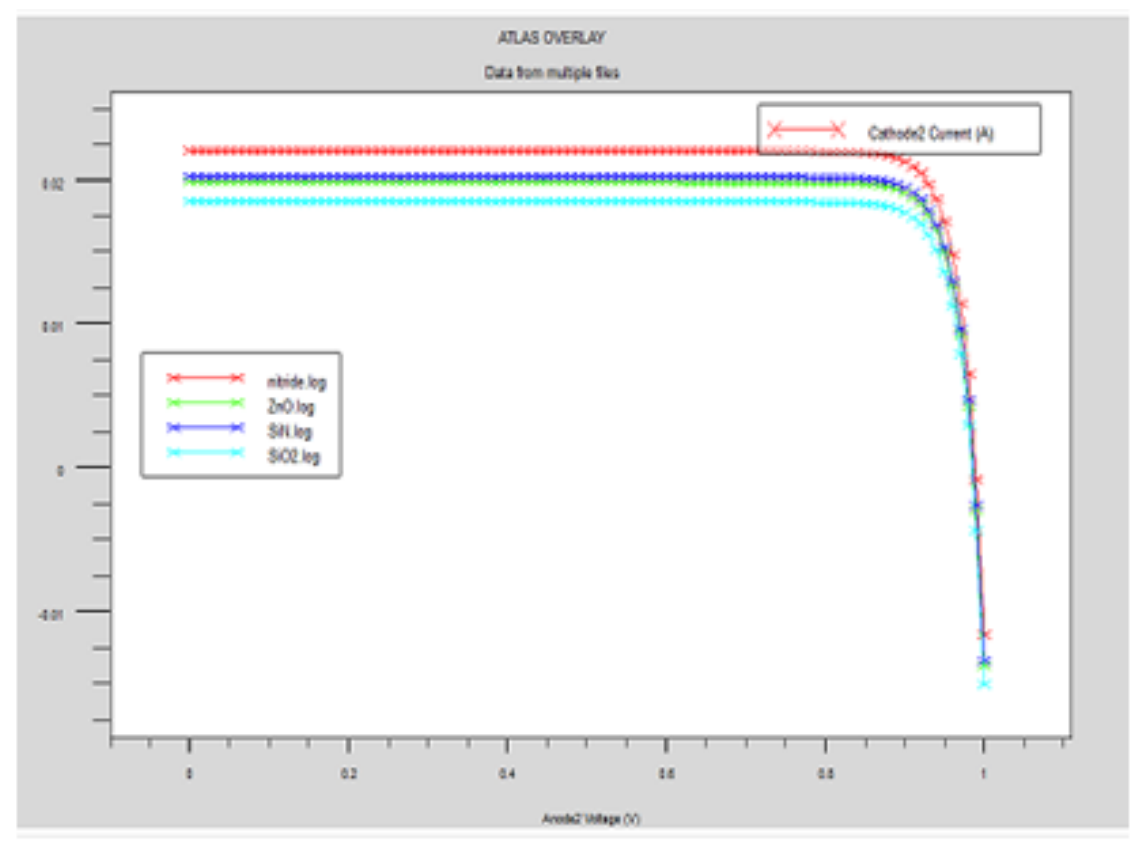

Figure3. Comparison of the performance of different anti-reflective coatings

The figure 4 shows the proposed cell structure by adding the $\mathrm{Si}_{3} \mathrm{~N}_{4}$ anti-reflective coating, and figure 5 shows the I-V curve of proposed structure with $\mathrm{Si}_{3} \mathrm{~N}_{4}$ anti-reflective coating.

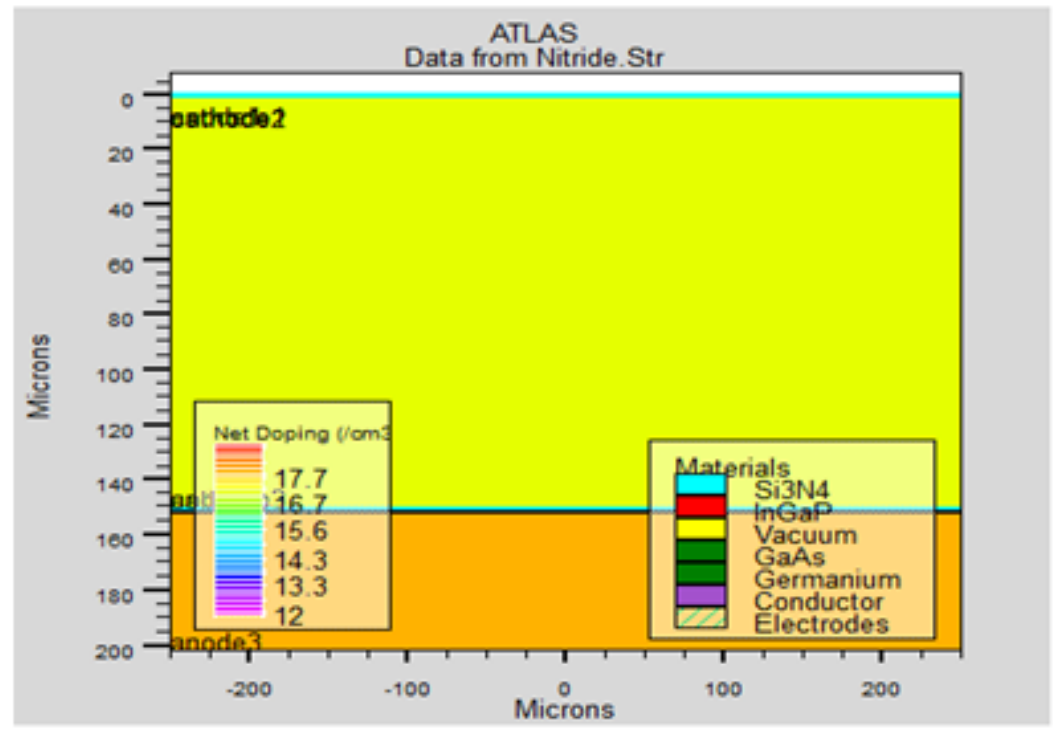

Figure4. The InGaP / GaAs / Ge solar cell structure by adding Si3N4 reflective coating. 


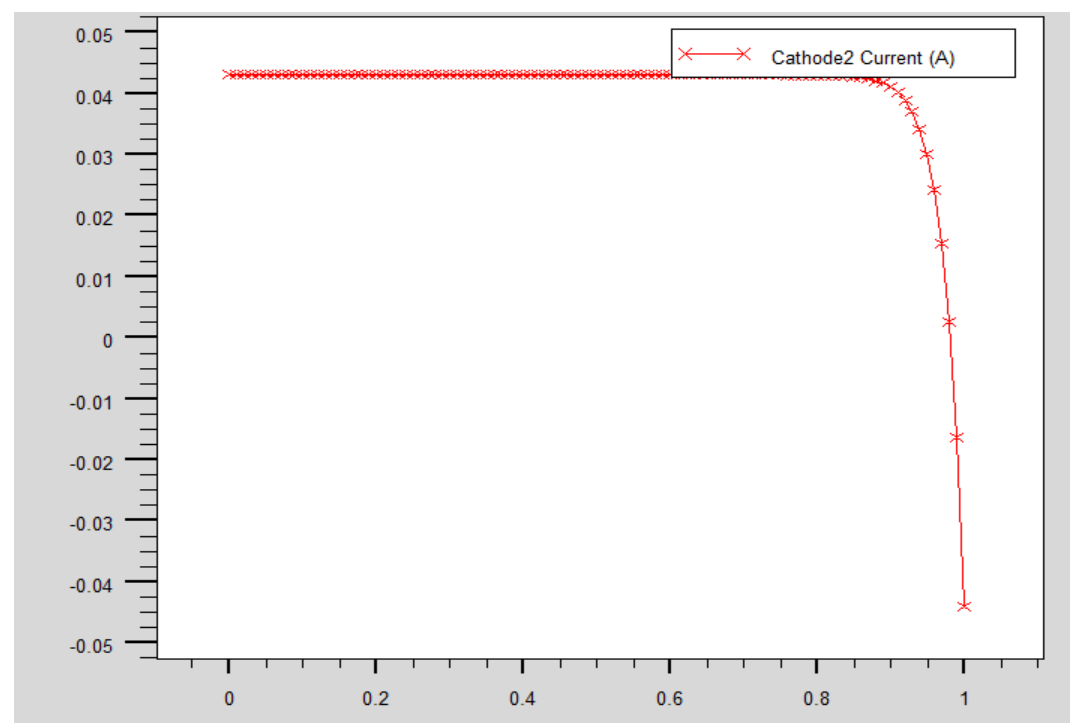

Figure5. The I-V curve of InGaP / GaAs / Ge solar cell with Si3N4 anti-reflective coating

\section{CONCLUSION}

In this paper, we examined and analyzed the structure and function of InGaP / GaAs / Ge solar cells. We have shown that GaAs single-link solar cells have a conversion efficiency of $21.97 \%$, which we were able to increase by $26.67 \%$ by adding the number of layers.

We also showed that changing the thickness and contamination of solar cell layers, like other electrical devices, has a significant effect on cell output, and with proper selection of these two factors, many parameters of the solar cell can be optimized.

Then we showed that by adding Anti Reflect Coating (ARC) the cell parameters were affected and we examined the effect of adding different anti-reflective coatings such as Si3N4, SiN, $\mathrm{ZnO}$ and $\mathrm{SiO} 2$ and we came to this conclusion. By placing the Si3N4 as an anti-reflective coating, we were able to achieve higher efficiency and filler coefficient.

Finally, we examined the effect of changing the impurity level of the layers along with adding the Si3N4 anti-reflective layer on the cell function and concluded that if we increase the impurity level of the middle layer of the cell and put a layer of Si3N4 anti-reflective coating on the cell. The yield will increase by $34.0788 \%$ and we will reach a shorter connection current and a higher open circuit voltage.

\section{REFERENCES}

[1] F. K. Glenn, Radiation Detection and Measurement. New York:Wiley, 1999.

[2] C. Schmelz, S. M.Bradbury, I. Holl, E. Lorenz, D. Renker, and S.Ziegler, IEEE Trans. Nucl. Sci., vol. 42, pp. 1080-1080,1995.

[3] Britvitch et al., - Avalanche photodiodes now and possible developments, ॥NIM A535, pp. 523-527,2004.

[4] D. Renker, - Properties of avalanche photodiodes for applications inhigh energy physics, astrophysics,and medical imaging,NIM A486,pp. 164-169, 2002.

[5] J. Pansarat, -Avalanche Photodiodes for particle detection,॥Nucl. Instr. Meth., vol. A 389 (, pp. 186-186, 1997.

[6] R. Lecomte, C. Pepin, D. Rouleau, A. Saoudi, M. S. Andreaceo, M.Casey, R. Nutt, H. Dautet, and P.P.Webb, IEEE Trans. Nucl. Sci., vol.45, pp. 478-478, 1998.

[7] R. Farrell, K. Shah, K. Vanderpuye, R. Graziaso, R. Myers, and G.Entine, Nucl. Instr. Meth., vol. A442, pp. 171-171, 2000.

[8] Bita Farhadi, Saba Ebrahimpanah, Rozita Farhadi, Younes Sohrabi, Tahereh Abasi, 2020, Numerical Simulation INGAP/GAAS Solar Cell with Hetero Tunnel Junction using A Thin Carbon Nano Tube Layer and Multi Quantum Well, INTERNATIONAL JOURNAL OF ENGINEERING RESEARCH \& TECHNOLOGY (IJERT) Volume 09, Issue 05 (May 2020). 
Improve the Efficiency and Open Circuit Voltage of Triple Junction Gaas Solar Cell with Anti Reflector Layer

[9] Bassetti Chandrasheker, Mahesh K, 2020, Improving Endurance of A Glider by using Solar Cells, INTERNATIONAL JOURNAL OF ENGINEERING RESEARCH \& TECHNOLOGY (IJERT) Volume 09, Issue 04 (April 2020).

[10] Haleshappa Davanagere, Jayarama A, 2019, Furan Based Electronic Materials for LED and Solar Cell Application, INTERNATIONAL JOURNAL OF ENGINEERING RESEARCH \& TECHNOLOGY (IJERT) RTESIT - 2019.

[11] Amit Kumar, Suraj Kumar, Sunil K. Choudhary, Vicky Kumar, 2016, Dye- Sensitized Perovskite Solar Cell, INTERNATIONAL JOURNAL OF ENGINEERING RESEARCH \& TECHNOLOGY (IJERT) CMRAES - 2016.

[12] Sudipta Banerjee, 2015, High Efficiency CdTe/CdS Thin Film Solar Cell, INTERNATIONAL JOURNAL OF ENGINEERING RESEARCH \& TECHNOLOGY (IJERT) Volume 04, Issue 09 (September 2015).

[13] Yastrebova , Natalya V." High- efficiency multi-junction solar cell : Current status and future potential." Solar Energy (2007)

[14] Sinton, R. A., A. Cuevas; "Contactless determination of current-voltage characteristics and minoritycarrier lifetimes in semiconductors from quasi-steady-state photo conductance data"; Applied Physics Letters, vol. 69, no. 17: AIP, pp. 2510-2512, 1996.

[15] Baruch, P., A. De Vos, P. T. Landsberg, J. E. Parrott; “On some thermodynamic aspects of photovoltaic solar energy conversion"; Solar Energy Materials and Solar Cells, vol. 36, pp. 201-222, 1995.

[16] S. J. Fonash, Solar Cell Device Physics (Second Edition) Elsevier, 2010

[17] King, R. R., D. C. Law, K. M. Edmondson, C. M. Fetzer, G. S. Kinsey, H. Yoon, R. A. Sherif, and N. H. Karam. "40\% efficient metamorphic GaInP/GaInAs/Ge multijunction solar cells." Applied physics letters 90 (2007): 183516.

[18] Yang, M. D., Y. K. Liu, J. L. Shen, C. H. Wu, C. A. Lin, W. H. Chang, H. H. Wang, H. I. Yeh, W. H. Chan, and W. J. Parak. "Improvement of conversion efficiency for multi-junction solar cells by incorporation of Au nanoclusters." Optics express 16, no. 20 (2008): 15754-15758.

[19] Lee, Chien-Ming, Sheng-Po Chang, Shoou-Jinn Chang, and Ching-In Wu. "Fabrication of High-Efficiency Silicon Solar Cells by Ion Implant Process." Int. J. Electrochem. Sci 8 (2013): 7634-7645.

[20] Dong-Sheng, Chen, Yang Jie, Xu Fei, Zhou Ping-Hua, Du Hui-Wei, Shi Jian-Wei, Yu Zheng-Shan, Zhang Yu-Hong, Brian Bartholomeusz, and Ma Zhong-Quan. "Performance improvement of CdS/Cu (In, Ga) Se2 solar cells after rapid thermal annealing." Chinese Physics B 22, no. 1 (2013): 018801.

[21] King, R. R., D. Bhusari, D. Larrabee, X-Q. Liu, E. Rehder, K. Edmondson, H. Cotal et al. "Solar cell generations over 40\% efficiency." Progress in Photovoltaics: Research and Applications 20, no. 6 (2012): 801-815.

[22] Abu Kowsar, Md, Sofikul Islam, Kazi Rizwana Mehzabeen, and Zahid Hasan Mahmood. "Applied Physics, Electronics and Communication Engineering, University of Dhaka, Bangladesh.* i-Automation, Dhaka-1216, Bangladesh.

[23] Hamedani, Pouya Fazel, Ahmad Taghinia, Foad Yazdi, and Zahra Mirmoeini Artimani. "Study the Effect of Varying the Thickness of Intermediate Band on the Intermediate Band Solar Cells Efficiency." Energy Procedia 14 (2012): 1496-1502.

[24] Kosten, Emily D., Jackson H. Atwater, James Parsons, Albert Polman, and Harry A. Atwater. "Highly efficient GaAs solar cells by limiting light emission angle." Light: Science \& Applications 2, no. 1 (2013): e45.

Citation: Rozita Farhadi, (2020)" Improve the Efficiency and Open Circuit Voltage of Triple Junction Gaas Solar Cell with Anti Reflector Layer", International Journal of Research Studies in Electrical and Electronics Engineering (IJRSEEE), 6(3), pp. 1-6. DOI: http://doi.org/10.20431/2454-9436.0603001

Copyright: (C) 2020 Rozita Farhadi, This is an open-access article distributed under the terms of the Creative Commons Attribution License, which permits unrestricted use, distribution, and reproduction in any medium, provided the original author and source are credited. 